\title{
Morphological Study on Room-Temperature-Cured PMMA-Grafted Natural Rubber-Toughened Epoxy/Layered Silicate Nanocomposite
}

\author{
N. Y. Yuhana, ${ }^{1}$ S. Ahmad, ${ }^{2}$ M. R. Kamal, ${ }^{3}$ S. C. Jana, ${ }^{4}$ and A. R. Shamsul Bahri ${ }^{5}$ \\ ${ }^{1}$ Department of Chemical and Process Engineering, Universiti Kebangsaan Malaysia, 43000 Selangor, Bangi, Malaysia \\ ${ }^{2}$ Department of Material Science, Universiti Kebangsaan Malaysia, 43000 Selangor, Bangi, Malaysia \\ ${ }^{3}$ Department of Chemical Engineering, McGill University, M. H. Wong Building, 3610 University Street, \\ Montreal, QC, Canada H3A $2 B 2$ \\ ${ }^{4}$ Department of Polymer Engineering, University of Akron, Akron, OH 44325-0301, USA \\ ${ }^{5}$ Crop Improvement and Protection Unit, Rubber Research Institute Experimental Station, 47000 Sungai Selangor, Buloh, Malaysia
}

Correspondence should be addressed to N. Y. Yuhana, yuliana@eng.ukm.my

Received 6 April 2012; Revised 6 June 2012; Accepted 6 June 2012

Academic Editor: Kin Tak Lau

Copyright () 2012 N. Y. Yuhana et al. This is an open access article distributed under the Creative Commons Attribution License, which permits unrestricted use, distribution, and reproduction in any medium, provided the original work is properly cited.

\begin{abstract}
A morphological study was conducted on ternary systems containing epoxy, PMMA-grafted natural rubber, and organic chemically modified montmorillonite (Cloisite 30B). Optical microscopy, transmission electron microscopy (TEM), scanning electron microscopy (SEM), energy dispersive X-ray (EDX), and wide-angle X-ray diffraction (WAXD) analysis were used. The following four materials were prepared at room temperature: cured unmodified epoxy, cured toughened epoxy, cured unmodified epoxy/Cloisite 30B nanocomposites, and cured toughened epoxy/Cloisite 30B nanocomposites. Mixing process was performed by mechanical stirring. Poly(etheramine) was used as the curing agent. The detailed TEM images revealed co-continuous and dispersed spherical rubber in the epoxy-rubber blend, suggesting a new proposed mechanism of phase separation. Highmagnification TEM analysis showed good interactions between rubber and Cloisite 30B in the ternary system. Also, it was found that rubber particles could enhance the separation of silicates layers. Both XRD and TEM analyses confirmed that the intercalation of Cloisite 30B was achieved. No distinct exfoliated silicates were observed by TEM. Aggregates of layered silicates (tactoids) were observed by SEM and EDX, in addition to TEM at low magnification. EDX analysis confirmed the presence of organic and inorganic elements in the binary and ternary epoxy systems containing Cloisite 30B.
\end{abstract}

\section{Introduction}

Epoxy resins are widely used as coating, adhesive, and composite matrices in the structural, building, and transportation industries due to their low cost, ease of processing, excellent adhesion and good mechanical, thermal and barrier properties. The reaction of the epoxy monomer with a variety of curing agents produces a wide range of product properties. Under optimum conditions of mixing with the curing agent, the cured epoxy material exhibits a threedimensional network structure [1]. Normally, the resulting structure leads to brittleness, due to the high cross-link density.
The common approach to deal with resin brittleness involves the incorporation of fibers, rubber and thermoplastic polymers, micro- or nano-fillers, and polyorganic siloxane to improve the fracture toughness $[2,3]$. The addition of rubber has been the most successful commercially. Ratna and Banthia [4] reviewed the use of liquid and preformed rubber particles. Liquid synthetic rubbery components have been used, such as carboxyl terminated butadiene-acrylonitrile (CTBN) [5-7], carboxylrandomized butadiene-acrylonitrile (CRBN) [8], hydroxylterminated polybutadiene (HTPB) [5-9], and hydroxylterminated butadiene-acrylonitrile (HTBN) rubber [8]. Chemically modified natural rubber, such as PMMA-grafted 
natural rubber and epoxidized liquid natural rubber have been also studied and used $[10,11]$.

The incorporation of nanometer-sized fillers in polymer matrices to improve thermal, mechanical, barrier, electrical, and optical properties has gained interest recently. The most common types of polymer nanocomposites incorporate silicate, carbon, or metal oxide nanoparticles. In polymer nanocomposites, a small amount of silicate nanoparticles (less than 5 wt.\%) is commonly used. The silicate types used include natural silicate (montmorillonite, hectorite, etc.) and synthetic silicate (laponite, magadiite, and fluorohectorite). However, the most commonly used and studied nanoclay is montmorillonite (MMT), a layered aluminosilicate. The interesting feature of the layered silicates is their high aspect ratio. Also, it is available in the market as an organically modified clay. This facilitates the dispersion of the layers in a polymer matrix, at the nanometer scale.

The arrangement of the silicate particles in the polymer matrix can be as microsized agglomerates, as in the case of common fillers, or as intercalated or exfoliated particles [3]. Normally, the above three structures could be observed in a single polymer/silicate nanocomposite. Hence, in order to study the polymer nanocomposite morphology, both microstructure and nanostructure must be observed and considered. The most common techniques used are wide angle X-ray diffraction (WAXD) and transmission electron microscope (TEM). Scanning electron microscopy (SEM) could also be used to explain the fracture toughness behavior of nanocomposite.

Epoxy/layered silicate nanocomposites exhibit improved thermal, barrier, and mechanical properties. However, the impact properties are reduced at high layered silicate loading. On the other hand, rubber toughened epoxy has excellent impact strength, while the most common shortcomings of the binary system are reduced modulus and glass transition temperature [10]. The decrease in flexural strength and modulus is due to the presence of some amount of rubber, which remains dissolved in the epoxy matrix. McEwan et al. [6] reported that the amount of water absorbed and the rate of water diffusion increase with the amount of modified rubber content in the binary system. Absorbed water acts as an effective plasticizer for the cured epoxy system, which limits its utilization in aerospace and marine applications and as an integrated circuit (IC) packaging material.

The incorporation of dispersed rubbery particles in a layered silicate/epoxy nanocomposite has received significant attention [3, 12-16]. Morphological studies of the microstructure and nanostructure of the ternary system represent a challenge, due to the complexity of multicomponent systems. Balakrishnan and Raghavan [14] carried out extensive work on the morphology of elastomer acrylic toughened epoxy silicate nanocomposites. They found that the clay aggregates are well dispersed and are fewer in the epoxy matrix than in the epoxy nanocomposite. The layered silicate sheets tended to align around the walls of the rubber particle. Thus, they suggested that this might help the particles to withstand additional stretching forces before failure could occur at the epoxy matrix-rubber particle interface. It was also proposed that the aligned clay particles acted as additional reinforcement to protect the interface from the external stretching force, thus promoting cavitation.

Ratna et al. [16] conducted TEM analysis on epoxy nanocomposites based on a combination of epoxy resin, hyper-branched epoxy (HBP) and a layered silicate. The TEM images showed distinct regions of silicate aggregates and HBP phase-separated regions. No silicate particles were observed in the HBP phase. It has been reported that, while good intercalation was obtained in nanocomposites of layered silicate and epoxy, the interlayer spacing of silicates was reduced in the ternary system involving CTBN toughened epoxy layered silicate nanocomposites [3]. The rubber, which was soluble in epoxy, could not intercalate the layered silicates as well as the epoxy resin did.

The current research reports the results of a study on the effects of both liquid natural rubber and layered silicates (i.e., montmorillonite) in epoxy on the morphology of the ternary system. The DGEBA-type epoxy is toughened with PMMAgrafted natural rubber latex and nanoclay (Cloisite 30B). The direct use of the chemically modified latex is favorable, since it is cheaper, easy to blend and eco-friendly, compared to the use of dried chemically modified rubber that requires volatile organic compounds such as toluene, methylethylketone, or dichloromethane for dissolution, prior to mixing with epoxy. The use of dried PMMA-grafted natural rubber to toughen epoxy was studied by Zainol et al. [10] and Rezaifard et al. [11]. In this paper, we report the morphology of roomtemperature-cured samples.

\section{Experimental}

2.1. Materials. Diglycidyl ether bisphenol A (DGEBA) epoxy resin, Epikote 828, was obtained from Hexion Specialty Chemicals, Korea. The epoxide equivalent weight was 187 $\mathrm{g} / \mathrm{mol}$.

The liquid curing agent, Baxxodur TM EC301 (formerly known as Polyetheramine D230), was supplied by BASF. The composition is alpha-(2-Aminomethylethyl)-omega(2-aminomethylethoxy)-poly(oxy(methyl-1,2-ethanediyl)).

The amine number, total amines, and water content per gram were $461.7 \mathrm{mg} \mathrm{KOH} / \mathrm{g}, 8.23 \mathrm{meq} / \mathrm{g}$, and $0.02 \mathrm{wt} . \%$, respectively. The amount of curing agent needed was calculated, based on the chemical "equivalent weight."

PMMA-grafted natural rubber Megatex 30 was obtained from Green HPSP (M) Sdn. Bhd. The designation 30 refers to the weight percentage of PMMA in the rubber latex. The chemically modified natural rubber is prepared by free radical grafting of methyl methacrylate on natural rubber in its latex form [11]. The content of water and other lowmolecular-weight molecules, such as ammonia and traces of unreacted MMA, was estimated at around $48 \%$ by weight of the liquid rubber. This was determined by weighing the dried natural rubber after drying the liquid rubber in a convection oven at $125^{\circ} \mathrm{C}$ for $1 \mathrm{hr}$. It was assumed that water and other low-molecular-weight molecules would evaporate during the mixing and curing process. Only a small amount of liquid Megatex 30 (5 gram per hundred grams of epoxy) was used.

The organically modified montmorillonite used was Cloisite 30B, purchased from Southern Clay Products, USA. 

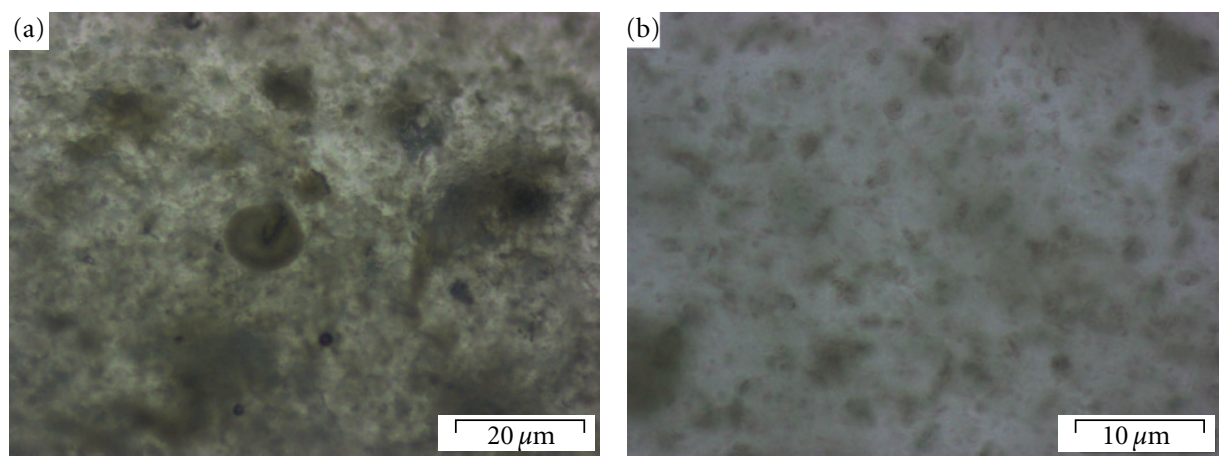

FIgURE 1: (a) and (b) illustrate the images of various sizes of rubber particles in epoxy mixtures, in the absence of curing agent.
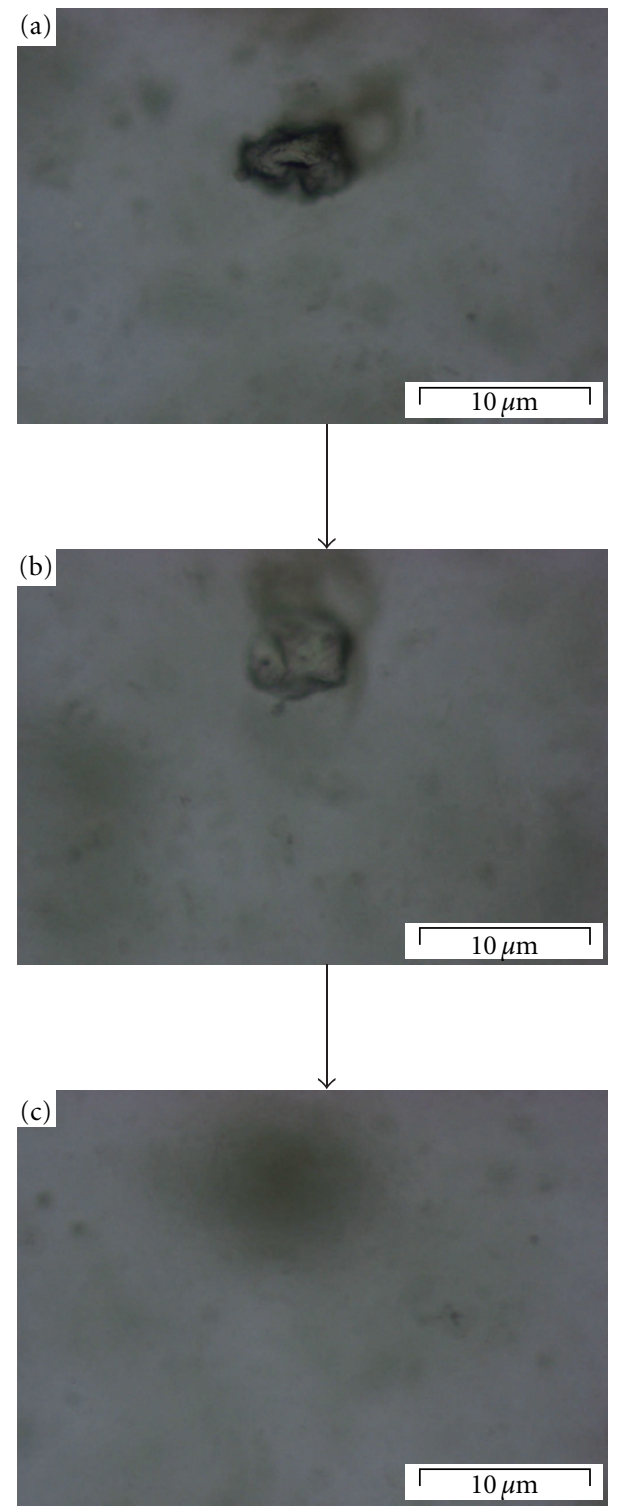

FIgURE 2: The images (a)-(c) show a morphology evolution process of a rubber particle which dissociates in the presence of curing agent, within approximate duration of 3 minutes.
TABLE 1: Composition of prepared samples.

\begin{tabular}{lccc}
\hline Name of sample & \multicolumn{3}{c}{ Weight of component (gram) } \\
& Epikote 828 & Megatex 30 & Cloisite 30B \\
\hline Epoxy & 100 & 0 & 0 \\
Epoxy-5 phr MG30 & 100 & 5 & 0 \\
Epoxy-5 phr Cloisite 30B & 100 & 0 & 5 \\
$\begin{array}{l}\text { Epoxy-5 phr MG30-5 phr } \\
\text { Cloisite 30B }\end{array}$ & 100 & 5 & 5 \\
\hline
\end{tabular}

The composition of the modifier is bis (hydroxyl ethyl) methyl tallow alkyl ammonium salts with montmorillonite. The organic decomposition onset temperature was $220^{\circ} \mathrm{C}$ [17].

2.2. Sample Preparation by Mechanical Stirring. The compositions of the four prepared systems are given in Table 1. One hundred grams of bisphenol A diglycidyl ether were added to a stainless steel cup. It was heated to about $55^{\circ} \mathrm{C}$ (must be less than $60^{\circ} \mathrm{C}$ to avoid peak exothermic heat) by using a hot plate. This was followed by the addition of Cloisite 30B or latex, and mechanical stirring using Stirrer LH (VELP Scientifica) and 3-vane propeller agitator at about $50 \mathrm{rpm}$ for about $1 \mathrm{hr}$. Higher speed and longer mixing time were found to produce more bubbles at the liquid surface. A stoichiometric amount of the liquid curing agent was then added and stirred for about 10 minutes. For the ternary system, the natural rubber in latex was added after 30 minutes of mixing Cloisite $30 \mathrm{~B}$ with the epoxy, and the mixture was stirred for another $30 \mathrm{~min}$ at $50-70 \mathrm{rpm}$. The total mixing duration of the ternary system was about $1 \mathrm{hr}$. The mixture was then cured at room temperature for a week.

2.3. Optical Microscopic Analysis. The liquid samples containing epoxy and rubber were analyzed, before and after mixing them with the curing agent. The samples were put on a microscope slide at room temperature. The images of the samples were viewed by using Olympus CX31 equipped with XCam- $\alpha$ camera and AnalySIS GetIT software.

2.4. Transmission Electron Microscopic (TEM) Analysis. The samples containing rubber were stained with osmium 


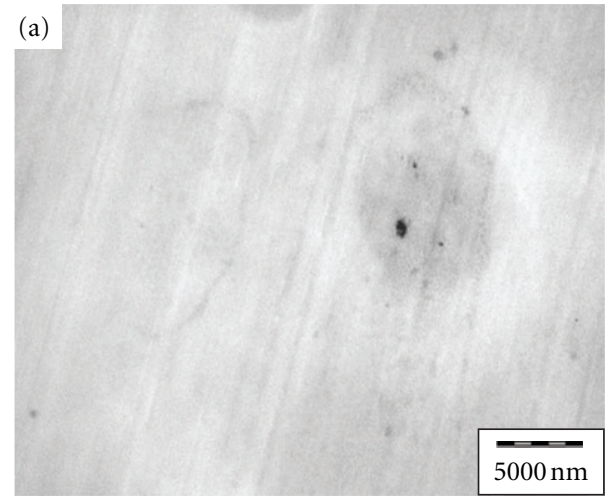

(b)

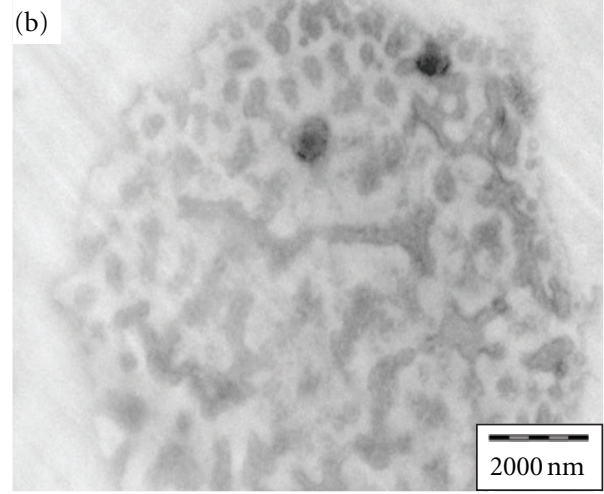

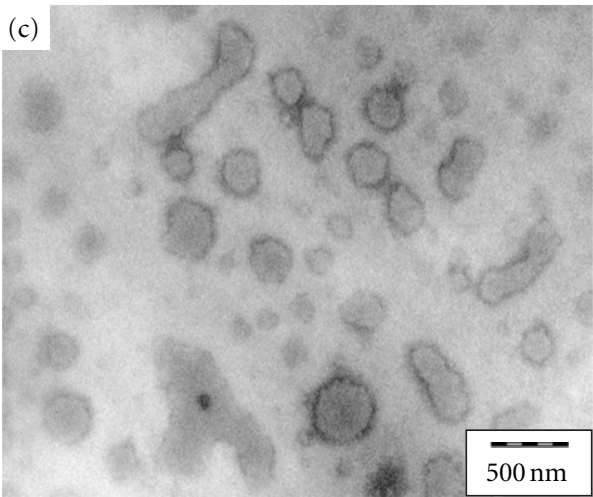

(d)

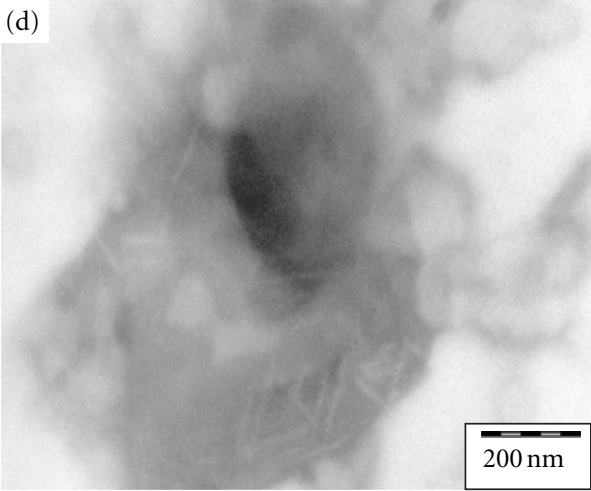

FIGURE 3: TEM images of PMMA-grafted natural rubber toughened epoxy showing (a) random distribution of rubber particle with various sizes within the epoxy matrix. (b) The co-continuous morphology of rubber particles. (c) Various shapes of rubber particles within the co-continuous phase. (d) Small rubber particles surrounding a dense rubber particle.

tetroxide for $1 \mathrm{hr}$ before cutting with a Reichert Ultracut E ultramicrotome, using a glass knife at room temperature. The 70-90 nm thick samples were collected on hexagonal 200 mesh copper grids, and the micrographs were obtained from two similar Philips TEM model CM12 with Soft Imaging Viewer software located at UKM and RRIM.

\subsection{Scanning Electron Microscopy (SEM) and Energy Dis-} perse X-Ray Analysis (EDX). The samples were fractured at room temperature to investigate the microstructure of the nanocomposite. The fracture surfaces were coated with thin layers of gold (about 90-100 ), prior to analysis. All specimens were examined with a Leo $1450 \mathrm{VP}$ SEM. The activation voltage varied from 2 to $5 \mathrm{kV}$. The EDX analysis was performed, using Oxford Instruments EDX model 7353, to study the dispersion of elements on the fractured samples.

2.6. Wide-Angle X-Ray Diffraction (WAXD). To study the dispersion of Cloisite 30B inside the epoxy, X-ray diffraction was conducted at room temperature, using a Bruker AXS D8 Advance $\mathrm{X}$-ray diffractometer. The X-ray beam was copperfiltered and radiation generated at operating conditions of $40 \mathrm{kV}$ and $40 \mathrm{~mA}$. The X-ray data were obtained from $2.3^{\circ}$ to $10^{\circ}(2 \theta)$ at a scan rate of $0.025^{\circ} / \mathrm{min}$. Thin specimens, about $1 \mathrm{~mm}$ thick, were analyzed. Cloisite 30B was also characterized to measure the initial d-spacing. The graphs were analyzed using Diffrac Plus (Release 2005) and Eva version 11 Rev. 0, supplied by Bruker Advance X-ray Solutions.

\section{Results and Discussion}

3.1. Optical Microscopic Analysis of PMMA-Grafted Natural Rubber-Epoxy Blends. The morphologies, observed by optical microscopic analysis of PMMA-grafted natural rubber/epoxy blend in the absence of curing agent, are illustrated in Figures 1(a) and 1(b). The random distribution of various sizes of rubber particles can be seen. It can be observed that dissociation of rubber occurs when curing agent is added to the epoxy/rubber blend mixtures. Figures 2(a)-2(c) shows a rubber particle, about $10 \mu \mathrm{m}$ in diameter, dissociating into smaller particles in approximately 3 minutes. It is suggested that this is due to spinodal decomposition. This is a spontaneous process to form interconnected particles from the parent phase.

3.2. TEM Analysis of PMMA-Grafted Natural RubberToughened Epoxy. The different morphologies observed by TEM analysis of unfilled PMMA-grafted natural rubbertoughened epoxy are illustrated in Figures 3 and 4 . Figure 3(a) is alow-magnification image showing the random distribution of rubber particles of various sizes within the epoxy matrix. There are clear regions where small rubber particles appear as a co-continuous phase, as shown in 

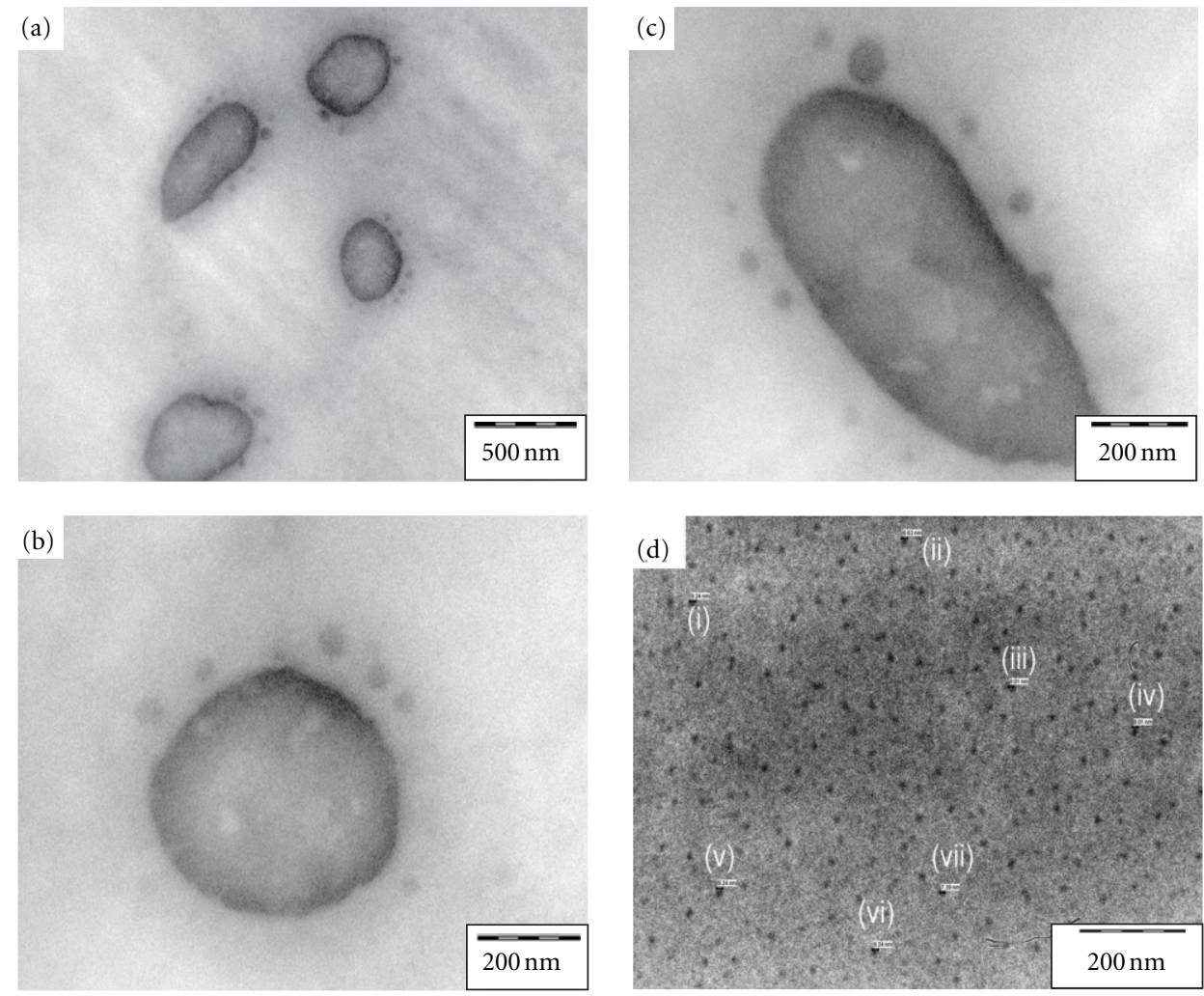

FIGURE 4: TEM images of PMMA-grafted natural rubber toughened epoxy showing (a) rubber particles located outside the co-continuous phase. (b) and (c) Rubber contains occluded epoxy phase. (d) Nanorubber particles, with about 40 nm interparticle distance. The estimated sizes of rubber particles are (i) 9.24, (ii) 8.63, (iii) 8.01, (iv) 8.01, (v) 9.24, (vi) 9.24, and (vii) $7.39 \mathrm{~nm}$.

Figure 3(b), and as isolated spherical rubber particles located outside the co-continuous phase, as shown in Figure 4(a).

Previous studies have indicated that the morphological parameters depend on chemistry, molecular weight, concentration of the liquid rubber, and the curing conditions [18]. Thomas et al. [9] described the variation of rubber particle sizes at difference epoxy cross-link density levels. Phase separation can occur according to two mechanisms: (i) spinodal decomposition and (ii) nucleation and growth. Kwon [19] studied and described the kinetics of phase separation of rubber particles. Yamanaka et al. [20] concluded that the morphology of cured epoxy-rubber blends appears in three types of two-phase structure, namely, uniform spherical domain structure, bimodal spherical domain structure, and co-continuous structure, depending on the curing condition such as the curing temperature and type of curing agent. They also suggested that the two-phase morphology can be controlled by studying the of phase separation and chemical reaction.

The co-continuous phase, as shown in Figure 3(b) consists of agglomerates of small rubber particles, approximately $200 \mathrm{~nm}$ diameter. It appears that rubber particles, about $10 \mu \mathrm{m}$ in diameter, dissociate into smaller particles. It is suggested that this is due to spinodal decomposition. This is a spontaneous process to form interconnected particles from the parent phase, which is thermodynamically in an unstable state. Unlike the spinodal decomposition, phase separation by nucleation and growth begins with formation of particles, that may accumulate to form an interconnected morphology. The interconnected morphology generated from both mechanisms forms a particle with a spherical envelop, to minimize the surface free energy. Yamanaka et al. [20] found that the stress-strain behavior of the cured resin with co-continuous structure does not exhibit a yield point, compared to that with spherical domain structure. On the other hand, the cured resin with co-continuous structure exhibits excellent vibrational damping efficiency.

The spherical rubber particles could be obtained by breaking up of the elongated particles, as shown in Figure 3(c). The image shows the rubber particles with imperfect spherical shape inside the co-continuous phase. The perfect spherically dispersed structure is difficult to attain, due to the high viscosity of the epoxy matrix.

Figure 3(d) shows two possible mechanisms of phase separation: (i) small rubber particles are attracted to a region with higher concentration of rubber particles (indicated by darker spots), which could reflect the nucleation and growth mechanism or (ii) the dissociation of rubber particles into small spherical particles. White lines/stripes are also present, which may contain cured epoxy or PMMA molecules. The size of the stripes is about $160 \mathrm{~nm} \times 10 \mathrm{~nm}$.

Rubber particles approximately $0.5 \mu \mathrm{m}$ diameter, surrounded by smaller particles could be observed in Figures $4(\mathrm{a})-4(\mathrm{c})$ beside the co-continuous phase. The 

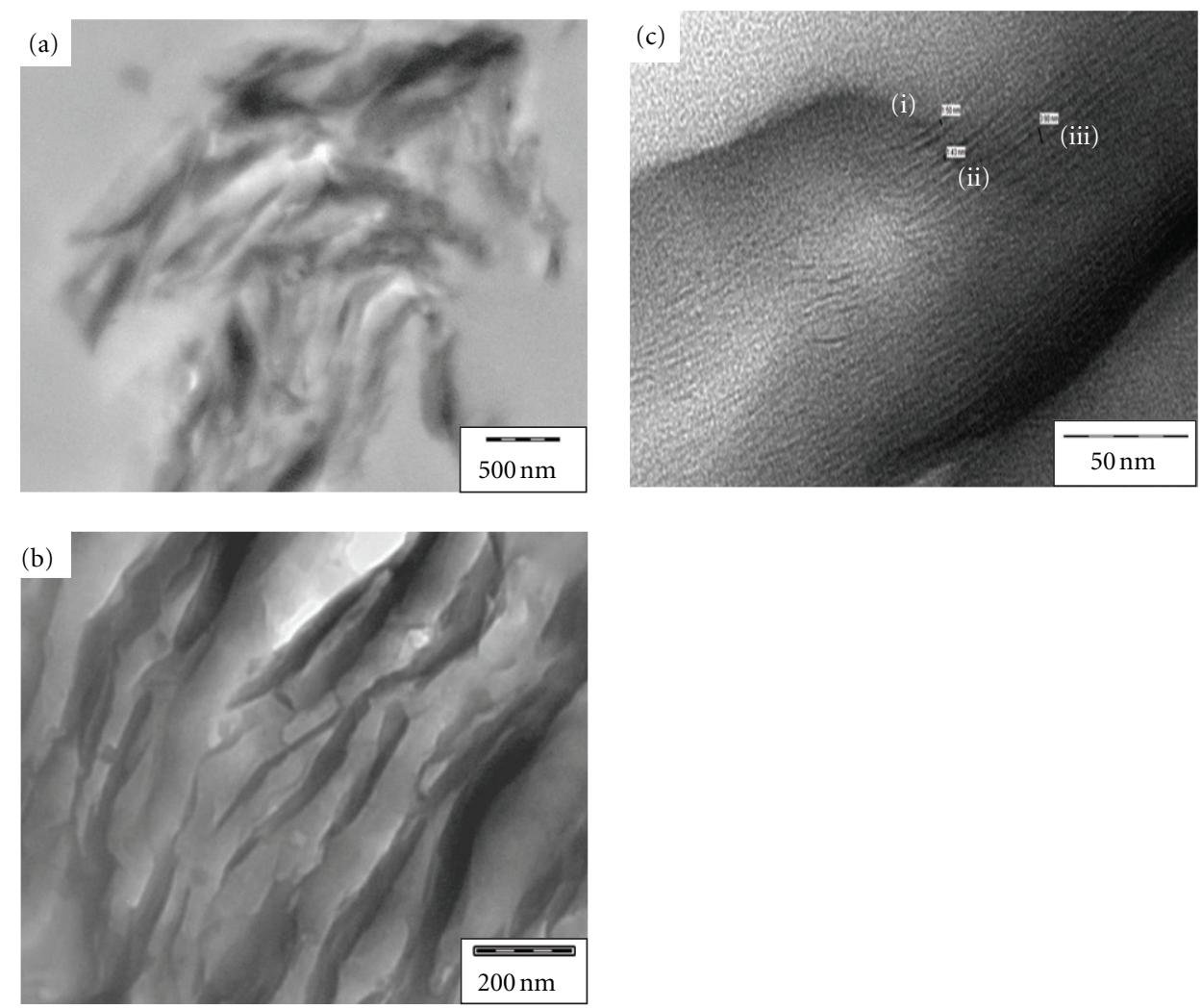

FIgure 5: TEM images of the cured epoxy, Cloisite 30B nanocomposite showing (a) and (b) Cloisite 30B aggregates in epoxy; they show the spatial distribution of exfoliated clay aggregates. (c) The intercalated structure of Cloisite 30B silicate layers, and the estimated interparticle distances are (i) 3.00 , (ii) 1.43 , and (iii) $3.90 \mathrm{~nm}$.

shape is mainly spherical. However, elongated or elliptical shapes could be observed. This may be due to the movement of the molecular chains during polymerization. The white spots on the surface of the particles could be the occluded epoxy phase in the rubber particles, as suggested by Russell and Chartoff [7]. This structure is preferred, since it is known that higher rubber particle volume fractions often lead to improved toughness.

The size of rubbery particles produced via reactioninduced phase separation is usually about $0.5-5 \mu \mathrm{m}$ in diameter with a volume fraction of 5-20\% [21, 22]. Zainol et al. [10], using SEM, observed that the average rubber particle size, obtained at low content of PMMA-grafted natural rubber ( 1 to $5 \mathrm{phr}$ ) was between 0.4 and $0.8 \mu \mathrm{m}$. In the present work, we also observed uniformly distributed rubber particles, with diameters ranging from 7-9nm, as shown in Figure 4(d). The interparticle distances are approximately $40 \mathrm{~nm}$. These particles were referred to as "dissolved particles" by other researchers [7].

\subsection{TEM Analysis of the Cured Epoxy, Cloisite 30B Nanocom-} posite. Figures 5(a) and 5(b) show poor dispersion of $5 \mathrm{phr}$ Cloisite 30B in the epoxy matrix, where silicates aggregates could be seen. They also show some cases of exfoliated and intercalated clay. The intercalated clay structure is illustrated at high magnification in Figure 5(c), with interparticle distances in the range 1.4 to $4 \mathrm{~nm}$. These estimates will be compared with XRD results later.

The clay dispersion could be improved by improving the mixing method. Becker and Simon [3], based on their work and that of other researchers, concluded that the interlayer spacing could be affected by shear mixing forces during cure. Mixing prior to the cure process and the use of solvents as processing aids were found to have little impact on the morphology of nanocomposite.

Interlayer expansion due to the intercalation of epoxy resin and curing agent inside the clay galleries was described by Chen et al. [23]. Also, they studied the evolution of rheological parameters as a function of cure time. They found that the interlayer expansion increased with duration of the isothermal cure reaction. Kong and Park [24] described the exfoliation process as a function of conversion. Jiankun et al. [25] explained that interlayer expansion occurs when the exothermal curing heat of cure of the epoxy resin in the gallery exceeds the endothermic heat to increase the interlayer spacing. Park and Jana [26] concluded that the elastic force exerted by cross-linked epoxy molecules within the clay galleries could influence the exfoliation of layered silicates.

3.4. TEM Analysis of PMMA-Grafted Natural RubberToughened Epoxy Layered Silicate (Cloisite 30B) Nanocomposite. TEM images show that the silicate layers and rubber 

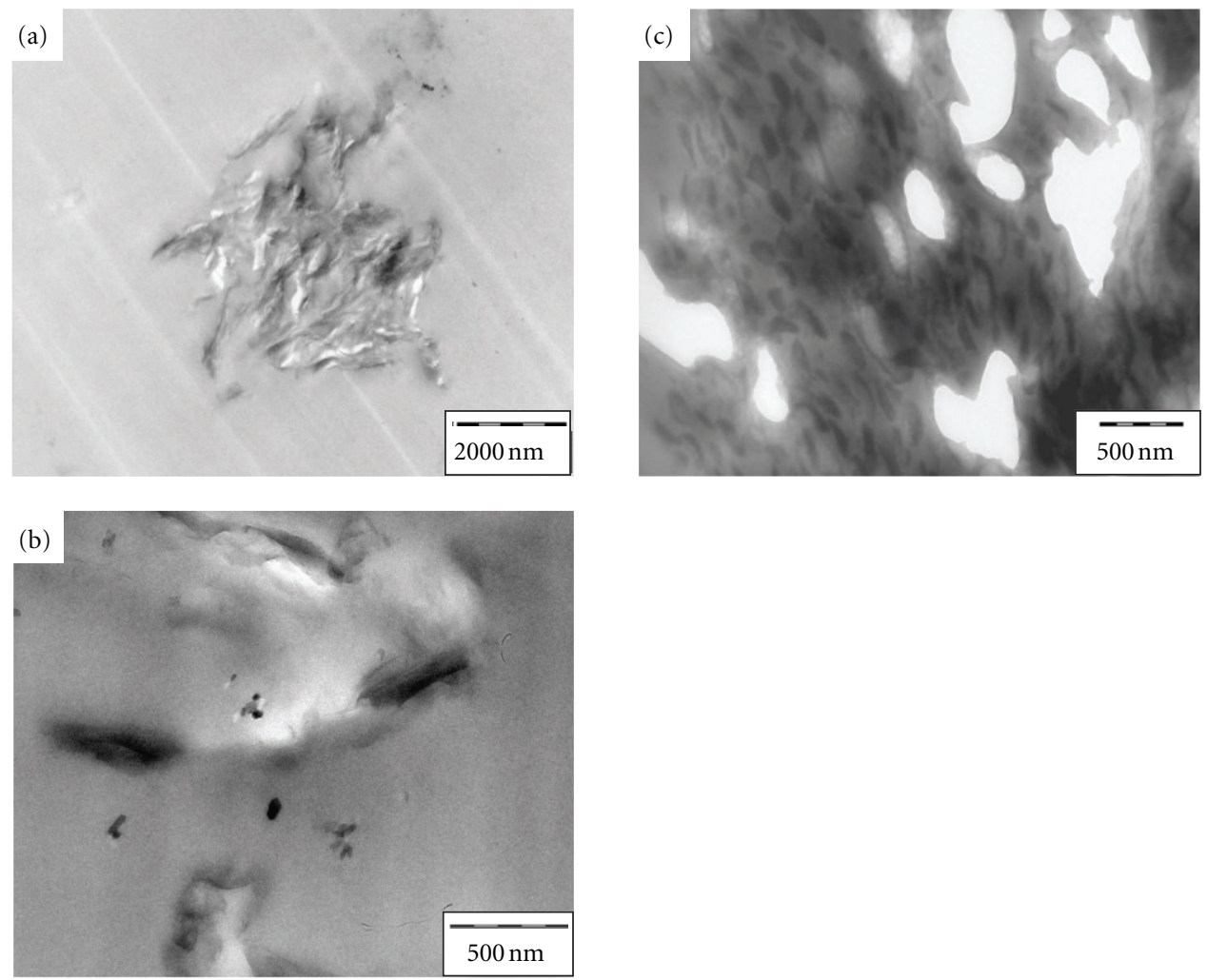

Figure 6: TEM images of PMMA-grafted, natural rubber-toughened epoxy layered silicate (Cloisite 30B) nanocomposite showing (a) and (b) clay aggregates and random distribution of rubber particles inside the epoxy matrix; (c) the presence of thin and ellipsoidal rubber particles inside the epoxy.

particles are not uniformly distributed in the epoxy matrix, as can be seen in Figures 6(a) and 6(b). This could be due to poor mixing and poor interaction between the silicate and rubber particles and poor overall silicate-rubber-epoxy interactions.

Figure 6(c) shows elliptical rubber particles with sizes around $40 \mathrm{~nm} \times 200 \mathrm{~nm}$. The voids are probably produced by the pull-out of the rubber particles from the epoxy, during cutting of the thin film. This seems to indicate poor adhesion between the rubber and epoxy phases, which is probably due to the presence of nanoclay around the rubber particles. Another possible factor could be the fast movement of high-molecular-weight epoxy during polymerization, in the presence the Cloisite $30 \mathrm{~B}$ layered silicate. This would result in pulling out the rubber particles into elongated or ellipsoidal shape. The high polymerization rate could be due to the catalyzing effect of organically modified silicate, as reported by Lan et al. [27]. Kwon [19] suggested another possible factor associated with the shearing action of the microtome knife.

The layered silicate aggregates surrounding the void were found to be well deagglomerated, and the clay was intercalated, with d-spacing of about 3-4 nm. Hence, the presence of rubber particles appears to enhance the separation of silicate layers. It has been proposed that the aligned clay particles act as additional reinforcement to protect the interface from the effects of an external stretching force, which promotes cavitation [15]. This can be seen in the present ternary system, as shown in Figure 7(a). Also, some smaller spherical particles, 4 to $8 \mathrm{~nm}$ in size could be seen in Figure $7(\mathrm{~b})$. They are smaller than the particles in the epoxyrubber blend, which are in the range $7-9 \mathrm{~nm}$. The smaller size of rubber particles in epoxy nanocomposites may be due to the shearing force by the silicate layers during the mixing process. The rubber nanoparticles could diffuse into the interlayer galleries and expand the interlayer distances of the organophilic silicates, during the phase separation and the dispersion of the silicate in the reaction mixture. However, this could not be confirmed in the images. In fact, Figures 7(a) and 7(b) show evidence of the influence of the clay particles on the shape of adjacent rubber particles, which change shape from spherical to ellipsoidal. As the organically modified layered silicate particles are adsorbed on the PMMA-grafted rubber particles, due to interactions between the polar groups, the shape of the rubber particles tends to follow the arrangement and alignment of the layered silicate.

The Cloisite 30B layered silicates are adsorbed on the rubber particles, as shown in Figures $7(\mathrm{c})$ and $7(\mathrm{~d})$. The silicate d-spacing near the rubber particles is about 3-4 nm. Thus, the rubber particles seem to assist in layer separation. Balakrishnan et al. [15], in their study of the morphology of preformed acrylic rubber dispersed silicate-filled epoxy nanocomposites, also found that the clay particles were 

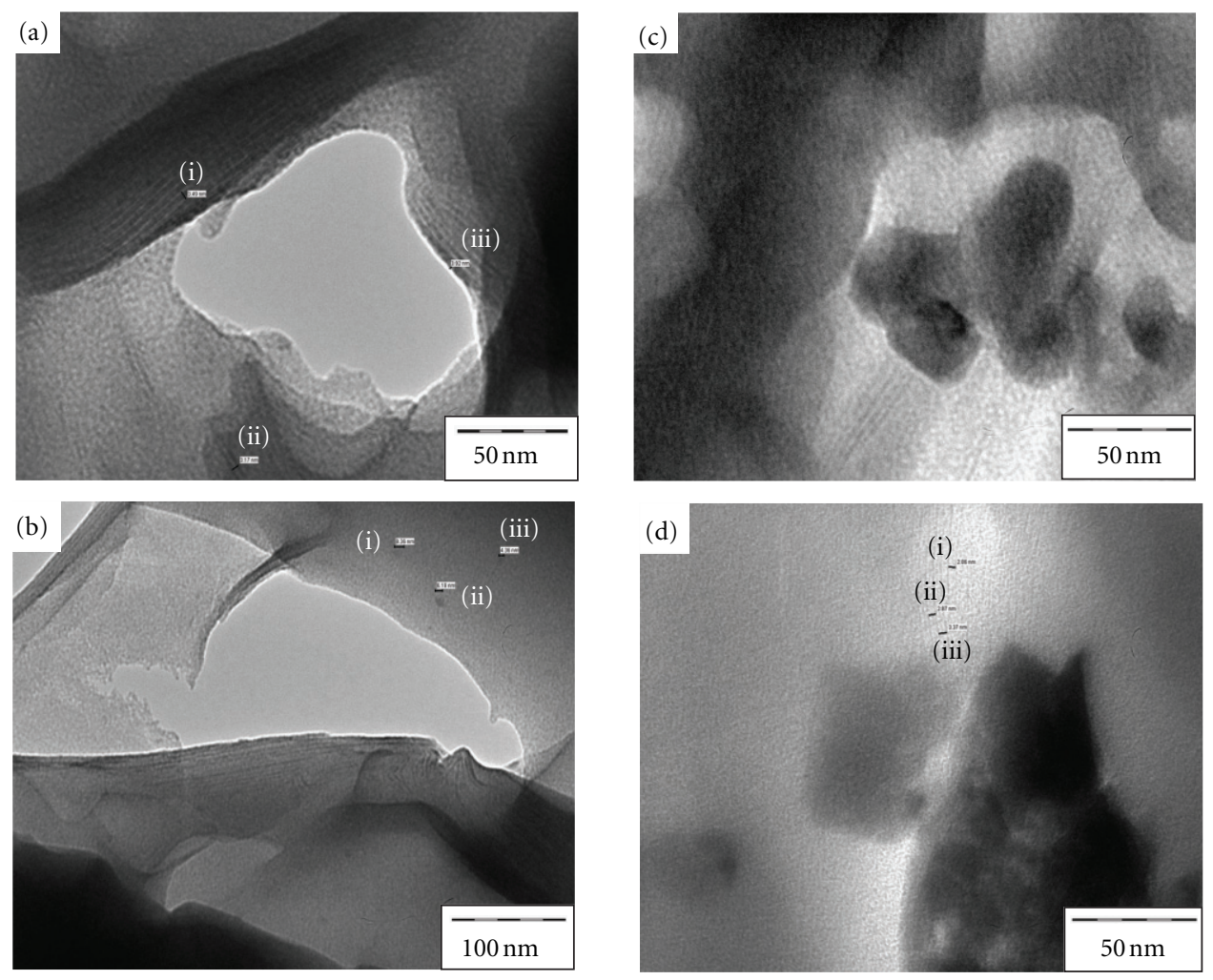

Figure 7: TEM images PMMA-grafted, natural rubber-toughened epoxy layered silicate (Cloisite 30B) nanocomposite showing (a) silicates around a cavity, with estimated interparticle distances of (i) 3.49 and (ii) $3.17 \mathrm{~nm}$; the distance between the cavity and a layered silicate is about (iii) $3.92 \mathrm{~nm}$; (b) the estimated rubber particle sizes are (i) 8.36, (ii) 6.18, and (iii) $4.36 \mathrm{~nm}$; (c and d) layered silicates are adsorbed on the rubber particles wall; (d) the estimated interlayer spacings are (i) 2.86, (ii) 2.87 , and (iii) $3.37 \mathrm{~nm}$.

located along the boundaries of rubber particles, but no further explanation was given.

Fröehlich et al. [13] suggested that the larger rubber particles undergoing phase separation assist the separation of silicate layers by diffusing into the silicate galleries. However, they did not produce evidence of this process. The results of the present work provide support for their suggestion, as shown by comparing the TEM images of Figures 5(c), $7(\mathrm{c})$, and $7(\mathrm{~d})$. The interlayer distance of the silicates is only about $1.4-4 \mathrm{~nm}$ in the binary system, compared to $3-4 \mathrm{~nm}$ in the ternary system. They also suggested that phase separation will be less likely in the region where silicate particle agglomerates are present. This is because the highest ammonium cations are present in that region. Thus, the epoxy polymerization rate is also high, and the fast curing process might prevent the phase separation of rubber particle. Also, the rubber molecules within the silicate galleries cannot agglomerate easily because of their restricted mobility.

3.5. SEM Analysis of Fracture Surface. The fracture surface of the unmodified epoxy was mainly featureless, except for a few river lines that can be seen in the crack-tip area (topleft of Figure 8(a)). According to the summary made by Huang et al. [28], based on reports of other researchers, the main deformation micromechanism in the fracture is very localized shear yielding in the crack-tip region.

Figure 8(b) shows that the size of rubber particles varied from approximately 5 to about $30-40 \mu \mathrm{m}$. Crack propagation was observed passing through the epoxy matrix (A) and rubber particles (B). The line (F) represents the crack energy propagation, which gradually reduces and terminates as it passes through rubber particles (C). The particles normally become distorted, but this is not observed in the Figure 8(b). This may be due to the strong bonding between the rubber particles and epoxy matrix. The stress concentration around the rubber particle is illustrated at (D). There is no reduction in the crack energy intensity as it is not propagated through the rubber particle (E). Thomas et al. [9] proposed an "elastomer pull-out" model that described the phenomenon of crack propagation in epoxies with high and low rubber contents. The model describes the shape of rubber particles, after crack propagation, which depends on the crack path, rubber percentage, and the interfacial adhesion with the matrix.

The possibility of crack growth termination is higher in the presence of large rubber particles. According to Kinloch and Hunston [29], the rubbery particles increase the fracture energy by facilitating a greater extent of energy dissipating deformations in the vicinity of the crack tip. 

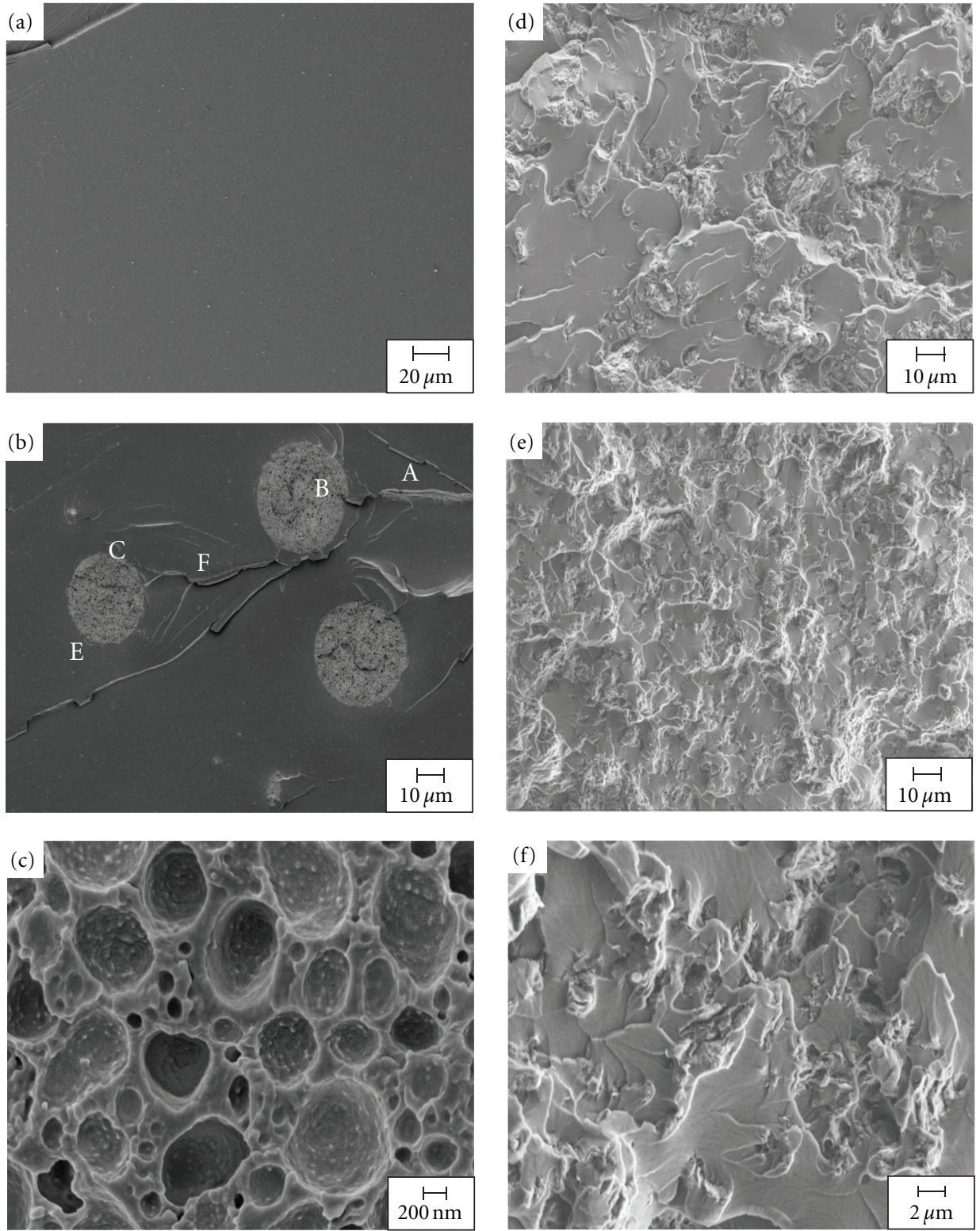

Figure 8: SEM images show the fracture surface of cured samples. (a) Neat epoxy. (b) Epoxy containing 5 phr MG 30 . (c) Pores or cavitation on the rubber particles. (d) Epoxy containing 5 phr Cloisite 30B. (e)-(f) Epoxy containing 5 phr MG30 and 5 phr Cloisite $30 B$.

The deformation processes are (i) cavitation in the rubber particle and (ii) multiple, but localized shear-yielding in the matrix, initiated by the stress concentrations associated with the rubbery particles. Rezaifard et al. [11], in their extensive studies on MG rubbers toughened epoxy, suggested four energy dispersive mechanisms which are responsible for retarding the fracture process. They were local cavitation in the rubber particles and the surrounding matrix, plastic shear yielding in the resin matrix, stretching and tearing of embedded rubber particles and the induction of a multilevel fracture path.

The cavitation process involves the initiation and growth of voids in the rubbery particles, which dissipates energy. Figure 8(c) shows the small cavities on the rubber particle surface. The inside surfaces of the cavities are rough with white spots inside, that look like bubbles tending to escape from the surface. They can be due to epoxy or other low-molecular-weight molecules, such as moisture, that are trapped inside the particles.

The clay is not uniformly distributed in the matrix, and the layered silicate aggregates could be observed clearly by using SEM, as shown in Figures 8(d) and 8(e). The images show more tortuous path for crack propagation around the areas of high concentration of silicate, compared to the case of epoxy-rubber systems and neat epoxies. Figure 8(e) shows that the fracture surfaces of epoxy containing MG30 and Cloisite 30B have a very rough texture, with multilevel fracture path. The rubber particle cavities are visible in 

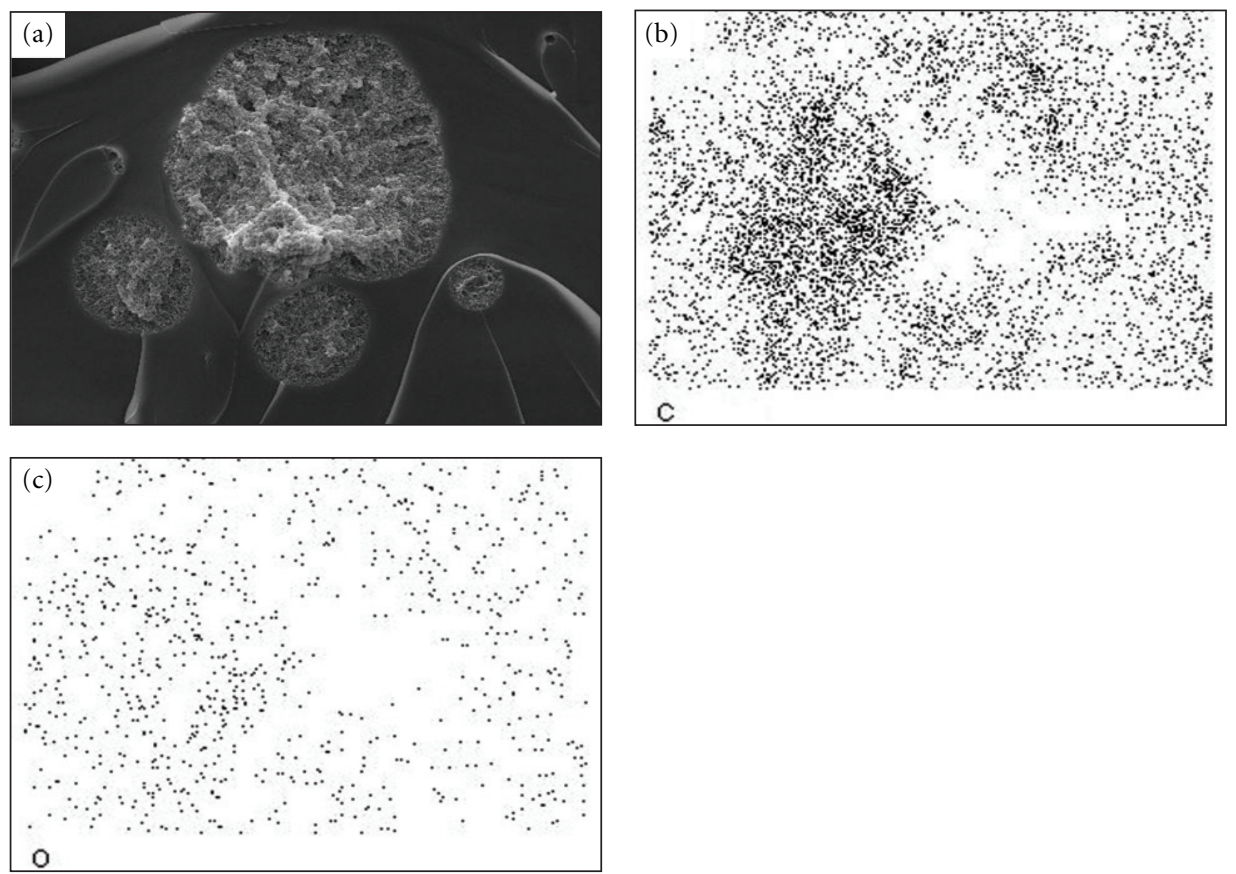

Figure 9: (a) Electronic image. (b) and (c) Mapping of the elements found on the image of epoxy 5 phr MG 30; O: oxygen and C: carbon.

TABLE 2: EDX analysis of all samples.

\begin{tabular}{lcccc}
\hline Element & Epoxy & Epoxy-5 phr MG30 & $\begin{array}{c}\text { Atomic\% (weight\%) } \\
\text { Epoxy-5 phr Cloisite 30B }\end{array}$ & Epoxy-5 phr MG30-5 phr Cloisite 30B \\
\hline $\mathrm{C}$ & $81.19(76.41)$ & $81.72(77.04)$ & $74.92(67.45)$ & $73.21(66.41)$ \\
$\mathrm{O}$ & $18.81(23.59)$ & $18.28(22.96)$ & $22.96(26.69)$ & $25.41(30.70)$ \\
$\mathrm{Si}$ & 0 & 0 & $1.98(4.16)$ & $0.99(2.10)$ \\
$\mathrm{Al}$ & 0 & 0 & $0.78(1.57)$ & $0.33(0.67)$ \\
$\mathrm{Mg}$ & 0 & 0 & $0.07(0.13)$ & $0.07(0.12)$ \\
\hline Totals & 100 & 100 & 100 & 100 \\
\hline
\end{tabular}

Figure $8(\mathrm{e})$. However, the rubber particles are not readily visible. This may be due to the formation of very small particle segments after the tearing and debonding process in the presence of layered silicate.

Liu et al. [12] reported that, at low layered silicates loading ( 3 phr), the fracture surfaces exhibited crack bifurcations, which were smaller and of low extent. This indicated that rubber toughening dominated the toughness of the material. However, on increasing the silicate loading to $6 \mathrm{phr}$, the rubber particles were not visible, and crack bifurcation was very strong. The cracks bifurcated, creating multiple fracture surfaces and causing greater energy dissipation.

Siebert et al. [30] reported that the addition of macrosized filler (tubular alumina and fumed silica) into CTBNtoughened epoxy did not alter the average size of rubber particles. Also, Bandyopadhyay [31] found that SEM images of epoxy containing both rubber and zirconia particles showed crack pinning, crack bowing and matrix deformation. Moreover, the zirconia particles acted as sources for slow crack initiation by debonding, tearing, and cavitation of rubber particles.
3.6. EDX Analysis. The presence and distribution of chemical elements on the fractured samples could be determined by using EDX, in which the software maps the elements found on the SEM image by X-ray analysis. It also permits estimation of the quantity of the elements in terms of atomic and weight percentages.

The EDX analysis for all samples is given in Table 2. The analysis shows a small increase in $\mathrm{C}$ atom percentages for Epoxy-5 phr MG30. This may be due to the presence of long chains of natural rubber (polybutadiene) in the sample. In the presence of Cloisite 30B in epoxy, the EDX analysis reflected the composition of the hybrid organicinorganic polymer composite, containing carbon, oxygen, silicon, aluminum, and magnesium.

Figures 9(b) and 9(c) show the carbon and oxygen atom distributions on a fractured sample of epoxy containing $5 \mathrm{phr}$ MG 30. The oxygen atom percentage increases, as the silicates are incorporated in the epoxy. The EDX results shown in Figures 10(d)-10(f), regarding silicon, aluminum and magnesium atom distributions, further support the observation of aggregates of silicate in the fractured samples. 

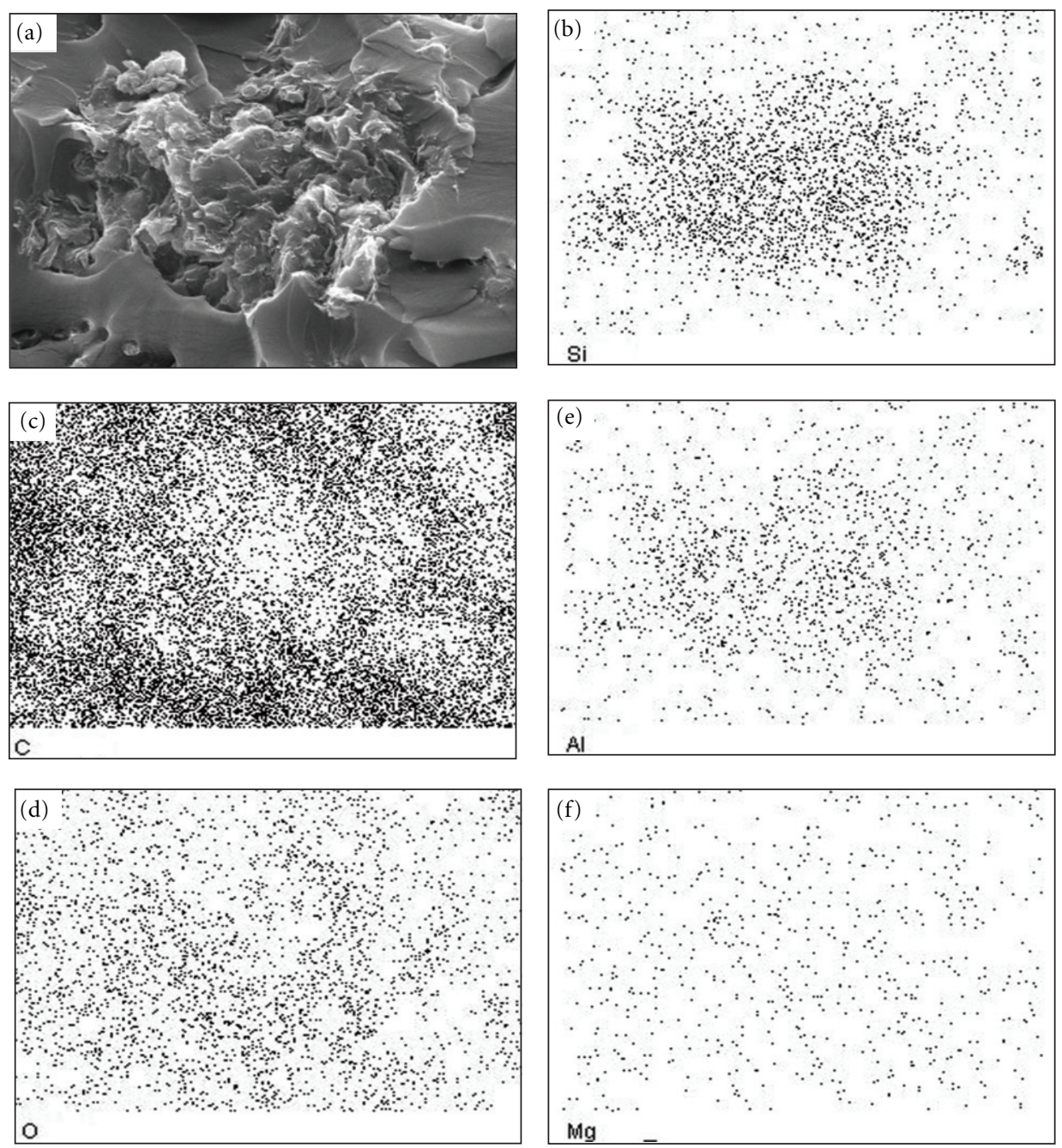

Figure 10: (a) Electronic image. (b)-(f) Mapping of elements found on the image of epoxy-5 phr Cloisite 30B.

It was not possible to determine whether the silicates preferably resided in the epoxy matrix or rubber particles, as illustrated in Figures 11(b)-11(f). This is due to the fact that the epoxy and PMMA-grafted natural rubber have similar main elements, which are carbon and oxygen. On the other hand, the silicate aggregates could be identified by observing the silicon and aluminum distributions in the image. The figures show that better dispersion occurs in the ternary system, compared to that in the binary system.

3.7. XRD Analysis. The XRD spectra of Cloisite 30B show a peak at $2 \theta=4.491^{\circ}$, indicating that the interlayer spacing of crystalline structure, $d_{001}$, is $19.66 \AA$. The peaks for various types of natural montmorillonite are in the range of $2 \theta=2.9$ to $6^{\circ}$, as shown in Figure 12(a). The XRD spectra of cured samples are given in Figure 12(b).

The cured epoxy is noncrystalline. However, the XRD spectra show the existence of crystalline structure at $2 \theta=$ $4.341^{\circ}$, with interlayer spacing of $20.34 \AA$. This may be due to the crystalline structure of low-molecular-weight molecules, such as the unreacted epoxy, polyetheramine, or others.
Improved mixing and higher curing temperature may result in a fully cured material.

The epoxy/rubber blend spectrum shows no sharp peaks in the range $2 \theta=3$ to $6^{\circ}$.

The XRD spectrum of epoxy containing $5 \mathrm{phr}$ Cloisite $30 \mathrm{~B}$ has a peak around $2 \theta=4.80\left(d_{001}=18.4 \AA\right)$. It is difficult to conclude that the peak is due to the silicate, since the neat epoxy spectrum does show a peak in the range. The "Search \& Match" tool was used to detect the presence of montmorillonite. It yielded a value of $2 \theta=4.925$ (17.93 $\AA$ ), which is considered to be due to the intercalated structure of silicate.

There is a peak in the XRD spectra of epoxy containing $5 \mathrm{phr}$ MG 30 and $5 \mathrm{phr}$ Cloisite 30B. It is not possible to conclude that this peak is due to the intercalated clays. The peak is around $2 \theta=4.925^{\circ}\left(d_{001}=17.93 \AA\right)$. From the XRD analysis, it can be concluded that the intercalated structure of Cloisite 30B might exist, with interlayer spacing about $18 \AA$ in the epoxy matrix, in both the absence or presence of rubber particles. Also, the presence of crystalline structure in epoxy is possible; hence, careful analysis of XRD is needed. 

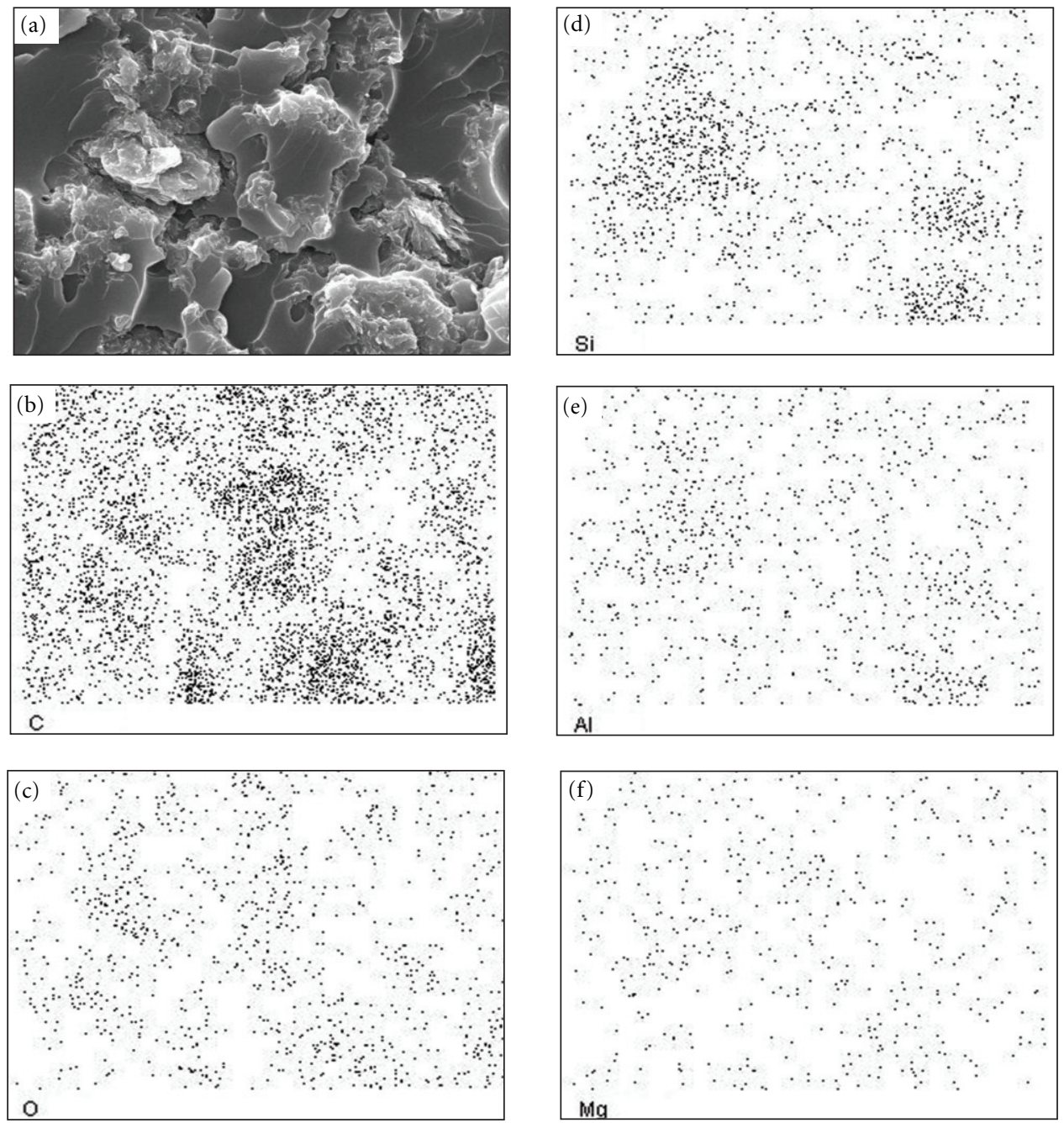

FIGURE 11: (a) Electronic image. (b)-(f) Mapping of elements found on the image of epoxy-5 phr MG30-5 phr Cloisite 30B.

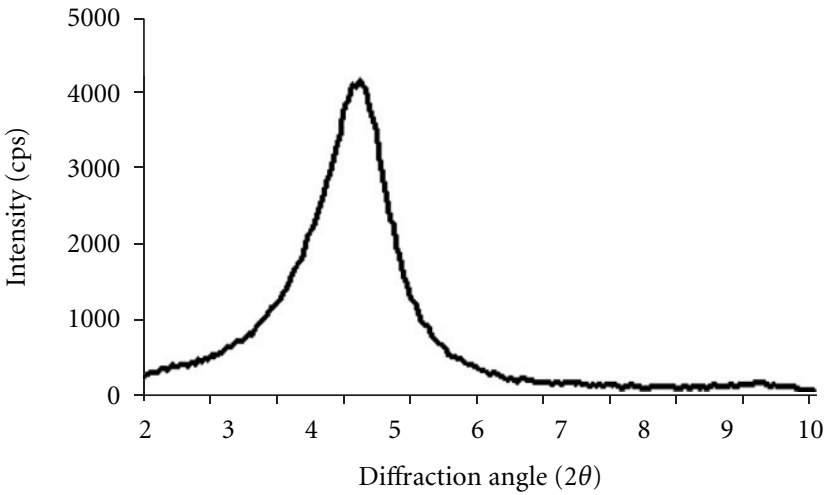

(a)

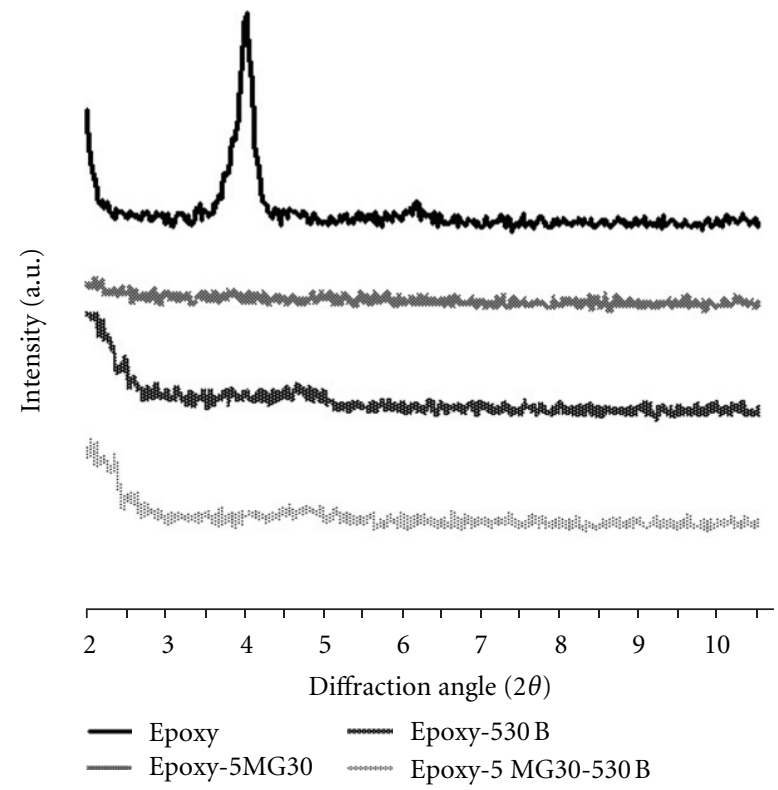

(b)

Figure 12: XRD spectra of (a) Cloisite 30B. (b) Cured samples of Epoxy, Epoxy-5 phr MG30, Epoxy-5 phr Cloisite 30B, and Epoxy-5 phr MG30-5 phr Cloisite 30B. 


\section{Conclusion}

Integrated optical microscopic study, TEM, SEM, WAXD, and EDX analyses are useful in describing and understanding the microstructure and nanostructure of nanocomposite morphology. Moreover, TEM provides insight regarding phase separation in epoxy/rubber blends and nanocomposites. It is proposed that spherical rubber particles could be formed from the dissociation of elongated particles. Also, small rubber particles may be attracted to points of high concentration of rubber molecules, eventually forming large rubber particles.

The size of rubber particles in the ternary system is smaller than in the binary system. This may be due to the shearing force exerted by the silicate layers during the mixing process. The rubber particles may assist the separation of layered silicates by diffusing between the layers. However, the rubber phase separation process could be hindered by the presence of the silicates. The shape of rubber particle could be influenced by the alignment of the surrounding layered silicates.

XRD can be used to detect the intercalated structure of layered silicates. Careful analysis is required, since the epoxy matrix could have crystalline structure, due to factors such as the presence of low-molecular-weight-molecule (i.e., epoxy, curing agent monomer, moisture, etc.) that depend on the mixing method, curing conditions, material history, and pretreatment conditions.

SEM analysis of fracture surface makes it possible to observe silicate aggregates in nanocomposite and the large cavitated size of rubber particles in epoxy-rubber blends. However, the rubber particles could not be observed in the ternary system. It is suggested that the improved fracture toughness of the ternary system may be due to the multiple fracture path observed in SEM images.

It is possible to determine the distributions of organic and inorganic elements on the fracture surface by using EDX. This is useful to evaluate the quality of dispersion of silicates.

The morphology study is useful to predict the properties of polymer composite. The mechanical, thermal, and barrier properties of the nanocomposite samples were discussed elsewhere $[32,33]$. We observed that the thermal stability and barrier properties of rubber toughened epoxy nanocomposites were improved, compared to the neat epoxy.

\section{Acknowledgments}

The authors would like to acknowledge help from Ms. Nor Maizana Zakaria from Rubber Research Institute of Malaysia, Ms. Suhaniza Razali, and Mr. Ahmad Zaki Zaini from Unit Mikroskopi of Universiti Kebangsaan Malaysia, and Mr. Zailan Mohd. Yusof for their kind assistance. Also, the authors wish to acknowledge Malaysia Public Service Department (PSD) and the Ministry of Science, Technology and Innovation (MOSTI) for SLAI scholarship, Science Fund Grant (03-01-02-SF0059) and OUP-FST-2012 grant to conduct the research.

\section{References}

[1] D. H. Kaelbe, "Physical \& chemical properties of cured resins," in Epoxy Resins: Chemistry and Technology, C. A. May and Y. Tanaka, Eds., p. 333, Marcel Dekker, New York, NY, USA, 1973.

[2] M. R. Zhang, A Review of the Epoxy Resin Toughening, Syracuse University, 2003.

[3] O. Becker and G. P. Simon, "Epoxy layered silicate nanocomposites," Advances in Polymer Science, vol. 179, pp. 29-82, 2005.

[4] D. Ratna and A. K. Banthia, "Rubber toughened epoxy," Macromolecular Research, vol. 12, no. 1, pp. 11-21, 2004.

[5] V. D. Ramos, H. M. da Costa, V. L. P. Soares, and R. S. V. Nascimento, "Modification of epoxy resin: a comparison of different types of elastomer," Polymer Testing, vol. 24, no. 3, pp. 387-394, 2005.

[6] I. McEwan, R. A. Pethrick, and S. J. Shaw, "Water absorption in a rubber-modified epoxy resin; carboxy terminated butadiene acrylonitrile-amine cured epoxy resin system," Polymer, vol. 40, no. 15 , pp. 4213-4222, 1999.

[7] B. Russell and R. Chartoff, "The influence of cure conditions on the morphology and phase distribution in a rubbermodified epoxy resin using scanning electron microscopy and atomic force microscopy," Polymer, vol. 46, no. 3, pp. 785-798, 2005.

[8] Z. Minfeng, S. Xudong, X. Huiquan et al., "Investigation of free volume and the interfacial, and toughening behavior for epoxy resin/rubber composites by positron annihilation," Radiation Physics and Chemistry, vol. 77, no. 3, pp. 245-251, 2008.

[9] R. Thomas, D. Yumei, H. Yuelong et al., "Miscibility, morphology, thermal, and mechanical properties of a DGEBA based epoxy resin toughened with a liquid rubber," Polymer, vol. 49, no. 1, pp. 278-294, 2008.

[10] I. Zainol, M. I. Ahmad, F. A. Zakaria, A. Ramli, H. F. A. Marzuki, and A. A. Aziz, "Modification of epoxy resin using liquid natural rubber," Materials Science Forum, vol. 517, pp. 272-274, 2006.

[11] A. H. Rezaifard, K. A. Hodd, D. A. Tod, and J. M. Barton, "Toughening epoxy resins with poly (methyl methacrylate)grafter-natural rubber, and its use in adhesive formulations," International Journal of Adhesion and Adhesives, vol. 14, no. 2, pp. 153-159, 1994.

[12] W. Liu, S. V. Hoa, and M. Pugh, "Morphology and performance of epoxy nanocomposites modified with organoclay and rubber," Polymer Engineering and Science, vol. 44, no. 6, pp. 1178-1186, 2004.

[13] J. Fröhlich, R. Thomann, O. Gryshchuk, J. Karger-Kocsis, and R. Mülhaupt, "High-performance epoxy hybrid nanocomposites containing organophilic layered silicates and compatibilized liquid rubber," Journal of Applied Polymer Science, vol. 92, no. 5, pp. 3088-3096, 2004.

[14] S. Balakrishnan and D. Raghavan, "Acrylic, elastomeric, particle-dispersed epoxy-clay hybrid nanocomposites: mechanical properties," Macromolecular Rapid Communications, vol. 25, no. 3, pp. 481-485, 2004.

[15] S. Balakrishnan, P. R. Start, D. Raghavan, and S. D. Hudson, "The influence of clay and elastomer concentration on the morphology and fracture energy of preformed acrylic rubber dispersed clay filled epoxy nanocomposites," Polymer, vol. 46, no. 25, pp. 11255-11262, 2005.

[16] D. Ratna, O. Becker, R. Krishnamurthy, G. P. Simon, and R. J. Varley, "Nanocomposites based on a combination of epoxy 
resin, hyperbranched epoxy and a layered silicate," Polymer, vol. 44, no. 24, pp. 7449-7457, 2003.

[17] R. A. Limited, Safety Data Sheet -CL30B, Rockwood Additives Limited, Widnes, UK, 2005.

[18] D. Ratna, "Phase separation in liquid rubber modified epoxy mixture. Relationship between curing conditions, morphology and ultimate behavior," Polymer, vol. 42, no. 9, pp. 4209 $4218,2001$.

[19] O. Kwon, Dissertation, Virginia Tech, 1998.

[20] K. Yamanaka, Y. Takagi, and T. Inoue, "Reaction-induced phase separation in rubber-modified epoxy resins," Polymer, vol. 30, no. 10, pp. 1839-1844, 1989.

[21] A. J. Kinloch, R. D. Mohammed, A. C. Taylor, C. Eger, S. Sprenger, and D. Egan, "The effect of silica nano particles and rubber particles on the toughness of multiphase thermosetting epoxy polymers," Journal of Materials Science, vol. 40, no. 18, pp. 5083-5086, 2005.

[22] A. J. Kinloch, "Toughening epoxy adhesives to meet today's challenges," MRS Bulletin, vol. 28, no. 6, pp. 445-448, 2003.

[23] J.-S. Chen, M. D. Poliks, C. K. Ober, Y. Zhang, U. Wiesner, and E. Giannelis, "Study of the interlayer expansion mechanism and thermal-mechanical properties of surface-initiated epoxy nanocomposites," Polymer, vol. 43, no. 18, pp. 4895-4904, 2002.

[24] D. Kong and C. E. Park, "Real time exfoliation behavior of clay layers in epoxy-clay nanocomposites," Chemistry of Materials, vol. 15, no. 2, pp. 419-424, 2003.

[25] L. Jiankun, K. Yucai, Q. Zongneng, and Y. Xiao-Su, "Study on intercalation and exfoliation behaviour of organoclay in epoxy resins," Journal of Polymer Science B, vol. 39, no. 1, pp. 115120, 2001.

[26] J. H. Park and S. C. Jana, "Mechanism of exfoliation of nanoclay particles in epoxy-clay nanocomposites," Macromolecules, vol. 36, no. 8, pp. 2758-2768, 2003.

[27] T. Lan, P. D. Kaviratna, and T. J. Pinnavaia, "Epoxy selfpolymerization in smectite clays," Journal of Physics and Chemistry of Solids, vol. 57, no. 6-8, pp. 1005-1010, 1996.

[28] Y. Huang, A. J. Kinloch, R. J. Bertsch, and A. R. Siebert, "Particle-matrix interfacial bonding," in Toughened Plastics 1, C. K. Riew and A. J. Kinloch, Eds., chapter 8, pp. 189-210, American Chemical Society, Washington, DC, USA, 1993.

[29] A. J. Kinloch and D. L. Hunston, "Effect of volume fraction of dispersed rubbery phase on the toughness of rubbertoughened epoxy polymers," Journal of Materials Science Letters, vol. 5, no. 12, pp. 1207-1209, 1986.

[30] A. R. Siebert, C. D. Guiley, and A. M. Eplin, "Mechanical and fracture properties," in Rubber Toughened Plastics, C. K. Riew, Ed., chapter 19, pp. 389-401, American Chemical Society, Washington, DC, USA, 1989.

[31] S. Bandyopadhyay, "Macroscopic fracture behavior," in Toughened Plastics 1, C. K. Riew and A. J. Kinloch, Eds., chapter 9, pp. 211-258, American Chemical Society, Washington, DC, USA, 1993.

[32] N. Y. Yuhana, S. Ahmad, M. R. Kamal, S. C. Jana, and A. R. S. Bahri, "The flexural properties and morphology of roomtemperature cured PMMA grafted natural rubber toughened epoxy layered silicate nanocomposite," in Proceedings of the International Conference on the Advancement of Materials and Nanotechnology, Kuala Lumpur, Malaysia, November 2010.

[33] N. Y. Yuhana, S. Ahmad, M. R. Kamal, S. C. Jana, and A. R. S. Bahri, Thermal and Barrier Properties of Room-Temperature Cured PMMA—grafted Natural Rubber-Toughened Epoxy / Layered Silicate Nanocomposite, 2011. 

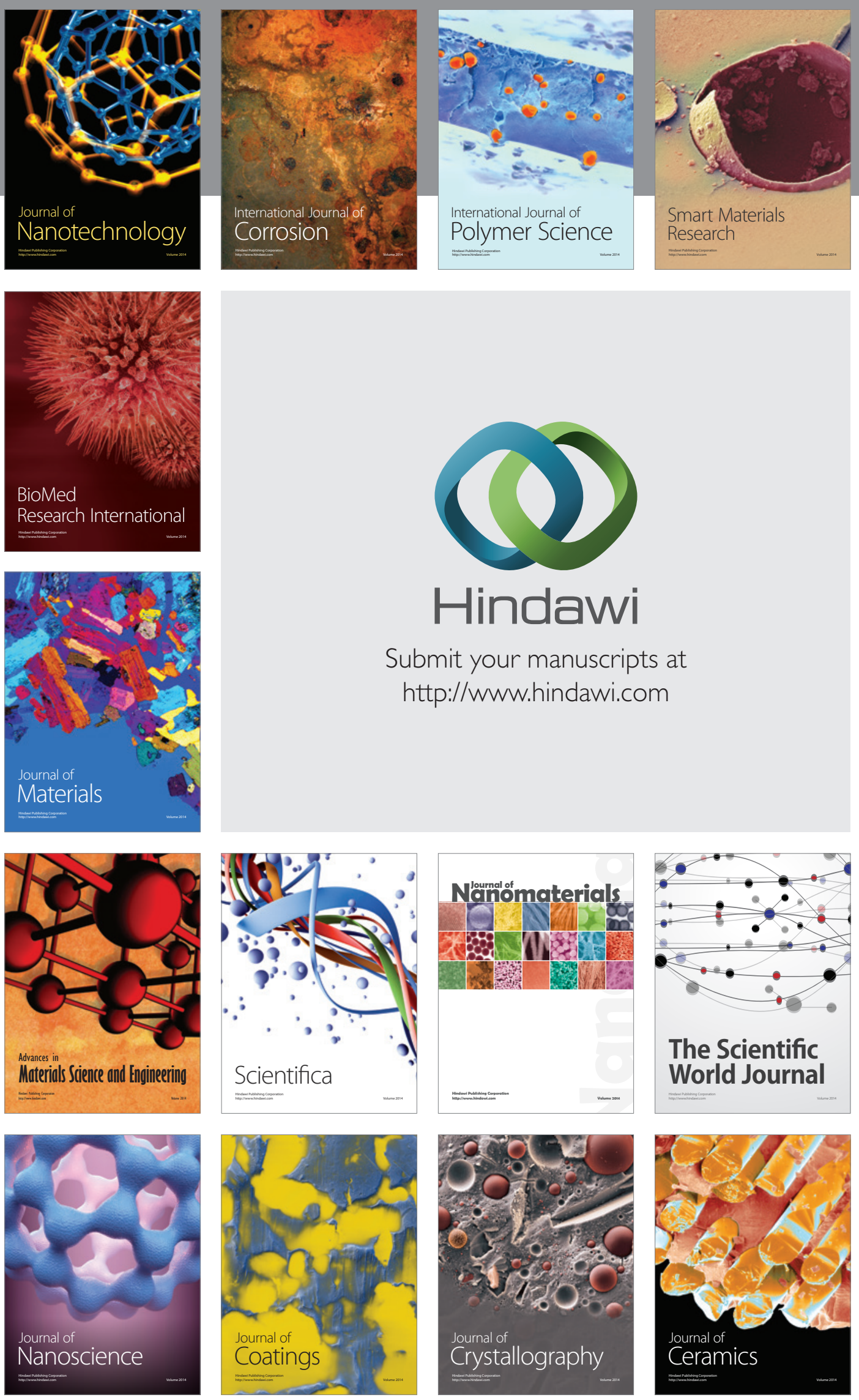

The Scientific World Journal

Submit your manuscripts at

http://www.hindawi.com

\section{World Journal}

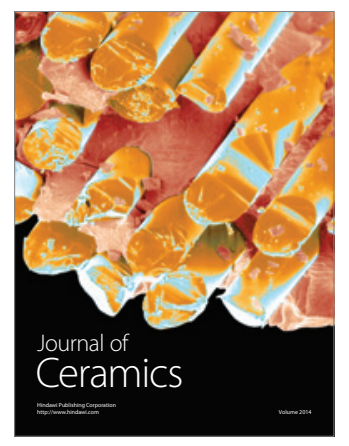

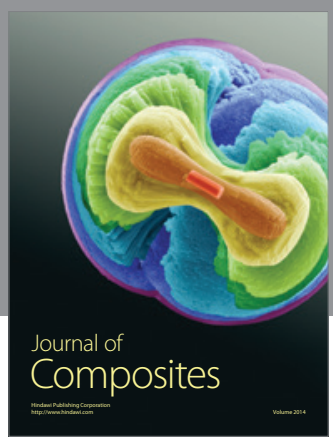
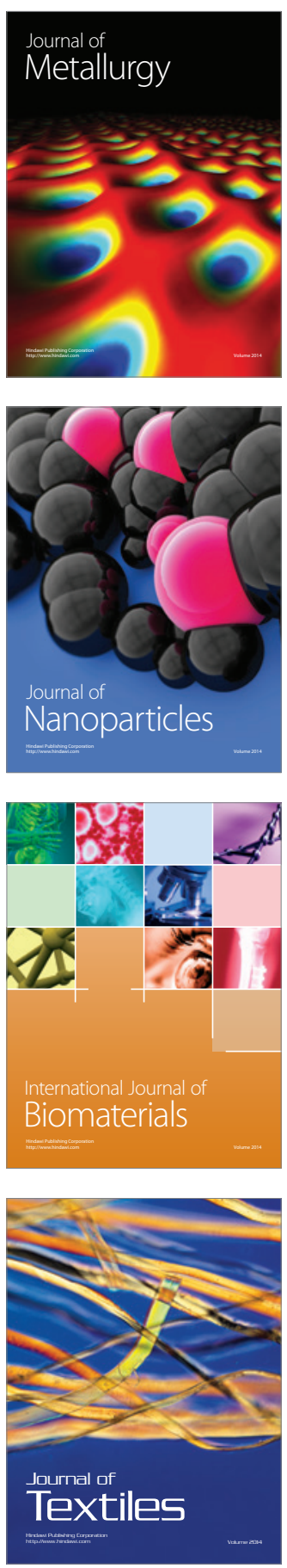